\title{
Ouvrage collectif sous la direction de F. Chapron et É. Delamotte : L'Éducation à la culture informationnelle
}

\section{Béatrice Micheau}

\section{CpenEdition}

\section{Journals}

Édition électronique

URL : http://journals.openedition.org/edc/2225

DOI : $10.4000 /$ edc.2225

ISSN : 2101-0366

Éditeur

Université de Lille

Édition imprimée

Date de publication : 1 décembre 2010

Pagination : 205-208

ISBN : 978-2-917562-04-8

ISSN : $1270-6841$

Référence électronique

Béatrice Micheau, «Ouvrage collectif sous la direction de F. Chapron et É. Delamotte : L'Éducation à la culture informationnelle », Études de communication [En ligne], 35 | 2010, mis en ligne le 02 février 2011 consulté le 21 septembre 2020. URL : http://journals.openedition.org/edc/2225 ; DOI : https://doi.org/ $10.4000 /$ edc. 2225

Ce document a été généré automatiquement le 21 septembre 2020

(c) Tous droits réservés 


\title{
Ouvrage collectif sous la direction de F. Chapron et É. Delamotte : L'Éducation à la culture informationnelle
}

\author{
Béatrice Micheau
}

\section{RÉFÉRENCE}

Ouvrage collectif sous la direction de F. Chapron et É. Delamotte : L'Éducation à la culture informationnelle, Actes du colloque international L'Éducation à la culture informationnelle.

1 Ouvrage collectif, sous la direction de Françoise Chapron et d'Éric Delamotte, L'Éducation à la culture informationnelle, est l'édition commentée des actes du colloque international du même nom, ayant eu lieu à Lille en octobre 2008.

2 En lien direct avec le travail de l'Erté «Culture Informationnelle et curriculum documentaire ", dont la préface d'Annette Béguin-Verbrugge rappelle, entre autres, le champ de travail et les objectifs, il permet à la fois de faire un bilan à mi-parcours des apports de cette équipe de recherche, et de croiser, confronter ces derniers à de nombreux regards extérieurs, nationaux, internationaux, et ceci à l'intersection de plusieurs disciplines, champs de recherche et territoires institutionnels.

Particulièrement riche, voire parfois hétérogène dans la modalité des contributions, ce livre se compose de cinq chapitres, dont l'ordre reconstruit pour l'essentiel la dynamique des recherches menées autour de l'Information Literacy. Dynamique qui articule questions sur les territoires et les objets de la notion de culture informationnelle et questions axiologiques, didactiques et curriculaires sur le projet d'une éducation à la culture informationnelle. Une des difficultés de la traduction de 
cette notion est ainsi d'incarner l'intrication concrète entre culture de l'information et éducation à l'information.

4 Ainsi le premier chapitre explore la pluralité de la notion de culture de l'information :

- en en soulevant la complexité et la polysémie ;

- en interrogeant les frontières de cette notion à laquelle s'agrège (pleinement ou à

la marge) éducation aux médias, informatique, culture numérique, documentation, maîtrise de l'information...;

- en questionnant la place relative de l'information, de la documentation, et de la communication dans les définitions;

- en réfléchissant aux enjeux de la culture informationnelle.

5 Le deuxième chapitre prolonge ces interrogations par des contributions internationales à la fois :

- pour éclaircir le concept d'Information Literacy et ses différentes traductions nationales et ainsi mieux appréhender les formes de cette culture ;

- pour connaître et comparer expériences et recherches internationales (venues du monde anglo-saxon pour l'essentiel) et ainsi éclairer l'évolution du système éducatif français ;

- pour comprendre l'expansion internationale de ce de domaine d'études, et ainsi dévoiler le lien entre ce développement et un volontarisme de politiques nationales et internationales en faveur du passage du «société de l'information» à une «société de la connaissance ».

6 Les trois derniers chapitres explorent plus précisément les différents axes de recherche de l'équipe de l'Erté.

Le chapitre III explore toujours la notion de culture informationnelle et ceci au travers des modes d'appropriation de l'information, des pratiques cognitives, mis en œuvre dans le cadre de dispositifs et/ou de systèmes info-documentaires. Il s'agit alors :

- d'étudier les environnements socio-techniques qui préside à l'organisation et à la circulation des informations, des connaissances ;

- de considérer les informations, les documents, les dispositifs techniques de production et de diffusion de l'information comme des formats incarnant matériellement des modèles d'apprentissage, de représentations du savoir, donc comme des objets sociaux;

- de modéliser les usages et pratiques des utilisateurs des systèmes d'information pour mieux comprendre les interactions entre apprenants, professionnels de l'information et dispositif (et en particulier les dispositifs numériques) ;

- de réfléchir aux approches info-communicationnelles et pédagogiques pouvant favoriser la qualité de ces interactions, et notamment la compréhension et l'appropriation de système documentaire institutionnalisé.

Le chapitre IV étudie plus précisément les pratiques documentaires informationnelles :

- en interrogeant spécifiquement la notion de pratiques et plus particulièrement les notions de pratiques sociales ordinaires ou pratiques informelles (normalement opposées à la notion de pratiques formelles) et définies ici comme pratiques non prescrites ;

- en étudiant conflits ou tensions, dans un contexte d'apprentissage, entre les représentations sociales des élèves, souvent vécues comme obstacles cognitifs, et les savoirs construits par et au sein de l'école, pour finalement favoriser des enseignements prenant consciemment appui sur ces représentations quitte à les déconstruire ;

- de dévoiler les implicites de la formation à l'information souvent fragmentaire car prise entre deux feux : le piège du formalisme réduisant parfois les apprentissages documentaires à des techniques, des procédures, des savoirs déclaratifs et le piège 
d'une dématérialisation faisant fi des contextes socio-techniques, des matérialités documentaires.

9 Le chapitre V, s'appuyant sur l'ensemble des éléments précédents, éclaire les enjeux d'une recherche en didactique autour de la notion de culture informationnelle dans un contexte où, malgré les discours performatifs d'une "société du savoir " à construire, les pouvoirs politiques prennent peu de décisions concrètes pour mettre en place des dispositifs spécifiques. Il s'agit alors :

- de questionner le lien entre didactique de l'information-documentation et didactique des disciplines ;

- de comprendre l'imbrication entre culture des médias et culture de l'information, pour mettre en place une didactique de l'éducation aux médias utiles à une éducation à l'information ;

- de réfléchir aux outils didactiques à mettre à disposition des enseignants pour favoriser la construction de savoirs fondamentaux en information-documentation. quelques axes structurant, et ceci en s'appuyant sur la trilogie « objet concret », " objet d'étude », « objet scientifique $»^{1}$ :

1. L'opposition entre une culture informationnelle qui serait de l'ordre du normatif, des savoirs constitués et institués et une culture informationnelle qui serait du côté des usages, des pratiques, de l'individu.

2. La volonté de dépasser cette opposition par un projet éducatif comprenant la culture informationnelle comme un dialogue entre «culture cultivée » et manière " de faire».

3. Dans le cadre de cette volonté, trois exigences dans l'approche de la culture informationnelle comme objet d'étude : privilégier les approches anthropologiques ou en tous les cas micro-sociales pour l'observation des pratiques, tenir compte des matérialités documentaires, des interactions entre l'homme et le dispositif et donc développer ou prendre en compte une pensée de la technique, croiser les domaines d'études pour mieux saisir un objet concret complexe (SIC, sciences de l'éducation, philosophie, informatique...).

4. La reconnaissance de la notion de culture informationnelle, comme objet scientifique vivant, complexe, polysémique, sujet à débat : et ce d'autant plus que comme objet concret et comme objet d'étude la culture informationnelle (et l'éducation à la culture informationnelle) sont aux prises avec des enjeux socioéconomqiues et des revendications d'identité professionnelle forts.

\section{NOTES}

1. Davallon Jean, Objet concret, objet scientifique, objet de recherche, in Hermès, 2004, $\mathrm{n}^{\circ} 38$. 


\section{AUTEUR}

BÉATRICE MICHEAU

Doctorante en SIC, Laboratoire GERiiCO, Université de Lille 3 